\title{
The Contradiction Between Low Cognitive Level and High Satisfaction Degree of Government Purchase of Old-Age Service
}

\author{
Hong-ting LIU \\ School of Humanities and Social Sciences \\ North China Electric Power University, Baoding, Hebei, China
}

Keywords: Government Purchases; Home Care Services; Estimation System.

\begin{abstract}
It is an inevitable choice for the government to purchase the old-age service, and the scientific evaluation system is of great significance to the government to purchase the pension service. However, the contradiction between the higher satisfaction degree of the elderly and the lower cognition level of the government to purchase the old-age service is significant, which greatly hinders the construction and perfection of the effective evaluation of the old-age service level system. In this paper, based on typical sampling, two embedded community nursing homes are selected to investigate and interview. It is found that there is a great contradiction between the elderly's satisfaction with the government's purchase of pension services and their cognitive level, and the phenomenon of high satisfaction and low cognitive level is prominent.
\end{abstract}

\section{Introduction}

Under the background of aging population, the traditional family pension function is weakened. Government purchase of home care services is the inevitable choice of rapid aging of the population. In the process of government transformation, it is of great significance to promote the purchase of home care services from social forces, and the scientific evaluation system is of great significance for the government to purchase home care services. However, the contradiction between the higher satisfaction degree of the elderly and the lower cognition level of the government to purchase the old-age service is significant, which greatly hinders the construction and perfection of the effective evaluation of the old-age service level system. Therefore, the government purchase home-based home care service evaluation system needs to be further standardized and scientific.

Government purchases of services are financed from the social welfare budget by public tender or direct funding for the purchase of welfare social services from various providers of social services [1]. In essence, government purchase is a mode of providing public goods and public services effectively by using market competition mechanism. The main reason for government purchasing services is that the government has changed the way of economic support to non-profit social organizations in the aspect of social welfare system, encouraging different social service organizations to participate in competition through competitive bidding and contracts. To achieve the purpose of improving service quality and social service organization efficiency [2].

As to how to evaluate the performance, American scholar Grizzle (1982) thought that the comprehensive government performance evaluation standard should include service supply efficiency, service supply quality, cost-benefit, the fairness of enjoying the service, the consistency of national policy and the stability of financial input [3]. Elinor Ostrom (2000) interpreted the government performance evaluation criteria as five aspects: economic efficiency, fair redistribution, fiscal balance, adaptability and responsibility [4]. However, in Chinese literature, Professor Cai Lihui (2002) thought that performance evaluation criteria were influenced by value orientation, efficiency, service quality, and social equity. Six aspects, such as public satisfaction and public responsibility, should be covered by performance evaluation indicators [5].

Public satisfaction plays a leading role in performance evaluation in government purchasing home care service. The degree of public satisfaction is directly related to the economic and social benefits of the project, and the guiding role of public satisfaction should not be ignored. In the analysis of public satisfaction, public expectation, perceived quality of service and perceived value with value orientation affect public satisfaction. Whether it is the establishment of the government 
purchasing home care service project or the performance evaluation, we should attach importance to the public perception quality, perceived value and public expectation. The reform of the home care service should start from the demand side and pay attention to the real needs of the public. To improve the satisfaction and happiness of the elderly in their old age[6]. Secondly, the cognitive level plays an important role in the performance evaluation. The level of cognition of the masses to the government purchase services is closely related to whether the evaluation results meet the needs of the public and to maintain the professionalism, so as to improve the cognitive level of the masses. Further government policies, strong support and advocacy, and the introduction of citizen participation in performance evaluation will be more conducive to monitoring and maintaining the long-term stability of the partnership [7].

The analysis of the literature shows that the existing research mainly has the following shortcomings: first, the research content is insufficient. (1) The research on the satisfaction degree of performance evaluation is less and limited to the surface research. Although our government is still in the exploratory stage of purchasing home care service, public satisfaction is a very important part of performance evaluation, and the research on it can understand the service demand of service object and the evaluation of service quality to improve the service level and promote better development more pertinently. (2) There are few researches related to the cognition of the service object. The cognition of service directly affects the expected level of service, and the high expectation level brought about by high cognition will make higher demands on the service providers and realize the real satisfaction of the elderly. At the same time, the importance of high-cognitive has been proved with the development of practice and received more and more attention. Second, there is a lack of research object. The research places are mainly concentrated in the areas where the economy is developing rapidly and the service has formed a certain pattern, such as Shanghai, Ningbo, Hefei, etc., but the exploration of the government purchase of the home care service is still in the initial stage. From these shortcomings, there is no doubt that this study has important theoretical and practical significance.

\section{Method}

In this study, the current situation and problems of embedded community nursing home are taken as the research object, and the service items, including full-time old-age service, are mainly selected to run in or near the community. Based on the actual situation and the need of research, this study mainly selects two eligible institutions, which are community public hospitals and private domestic service institutions.

Baoding City's government purchase of home care services started in 2015, and is still in the exploration stage. According to the survey, the Baoding municipal government's service for the elderly aged 60 and above was purchased by the municipal government. In 2016, all the elderly who received the services were divided into two districts to facilitate management. Services are provided by two successful institutions, a public hospital and a private domestic service. The service content is divided into domestic service and medical service, in domestic service, the service content is cleaning glass, cleaning table, cleaning kitchen and other basic housework; in the part of medical service, it is mainly composed of physical examination.

In this study, the representative embedded community micro-nursing home - YY Home Co., Ltd and JX Hospital were investigated on the spot. In this paper, an in-depth interview was conducted with two heads of institutions, 30 nursing staff and 82 residents of the elderly, 10 members of the community neighborhood committee staff and 23 elderly people in the community. In this study, 202 questionnaires were completed, 199 valid questionnaires were recovered, and the effective recovery rate was $98.5 \%$. Random sampling method was used to sample the elderly who were served in the field research institutions. The questionnaire is divided into four parts, including: the basic information of the elderly, the reasons of being willing to be admitted to the embedded community micro-nursing home, the satisfaction factor and the dissatisfactory factor of the institution. The sampling method is simple random sampling. Because of the low level of education, the interview questionnaire is used to collect the data. Through field research, the information was 
obtained in real and effective ways. A preliminary understanding of the status quo, development characteristics, difficulties and shortcomings of embedded community nursing home and its countermeasures.

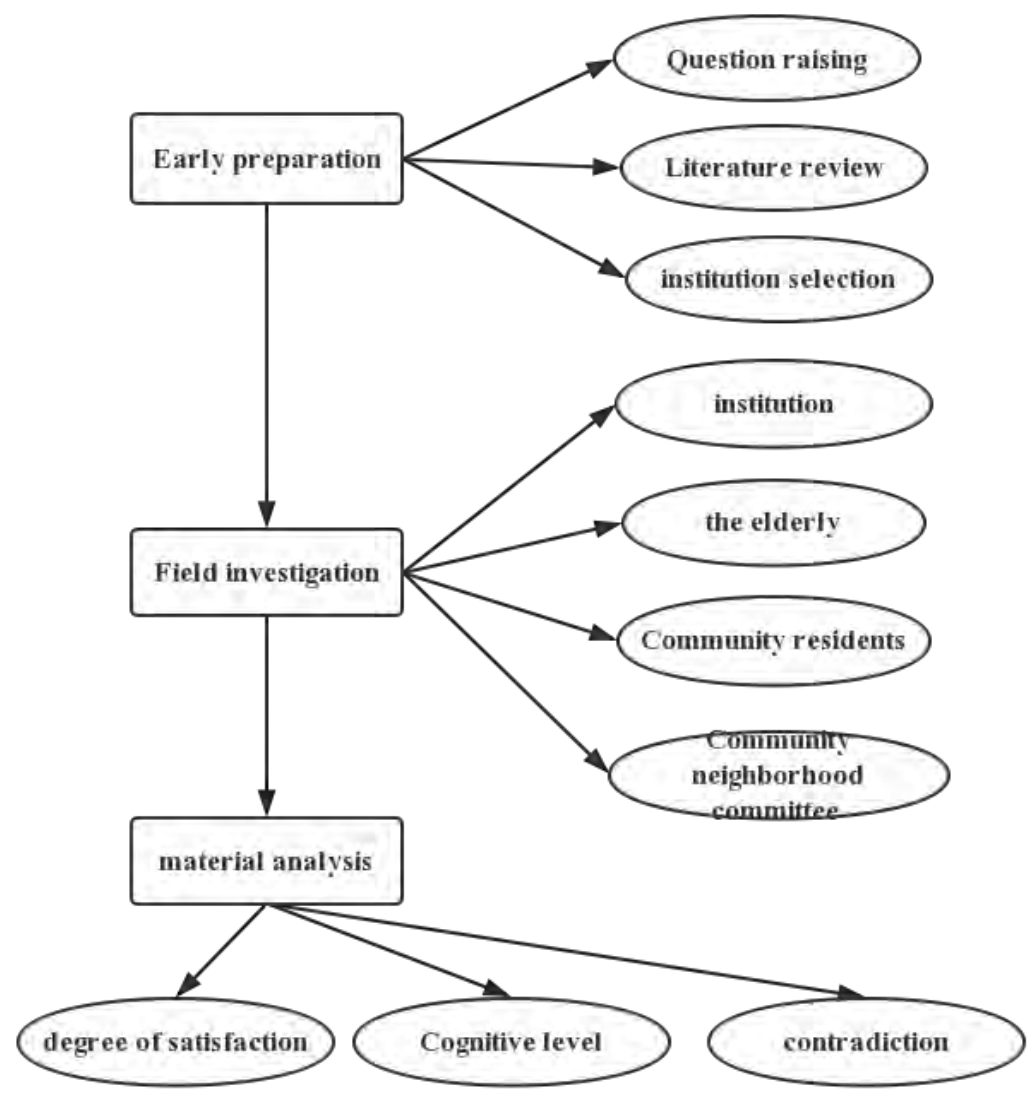

Figure 1. Research ideas

\section{Results}

1. High degree of satisfaction in the government's purchase of home care services

Table 1. Elderly people's satisfaction with the government's purchase of home care services

\begin{tabular}{lccc}
\hline Variable & Very satisfied & satisfied & Average and below \\
\hline $\begin{array}{l}\text { Overall satisfaction level } \\
\text { Institution }\end{array}$ & 71.51 & 22.58 & 5.92 \\
Service charge level & 84.62 & & \\
Service quality & 88.17 & 8.97 & 6.41 \\
Staff & & 8.60 & 3.22 \\
Attitude of staff & 89.30 & & \\
level of expertise & 91.30 & 8.02 & 2.67 \\
Service content & & 5.43 & 3.26 \\
Diversity & 89.78 & 6.455 & 2.15 \\
Necessity & 93.05 & 4.28 & 1.07 \\
Service frequency & 77.30 & 17.30 & 5.40 \\
Service timeliness & 78.48 & 15.19 & 6.33 \\
Service complaint channel & 84.85 & 7.88 & 6.06 \\
\hline
\end{tabular}

It can be seen from the table 1 that the elderly show a high degree of satisfaction from all aspects of the government's purchase of home care services. Specifically, in terms of the overall satisfaction 
of the elderly with the government's purchase of the home care service, the elderly who expressed "very satisfied" with the government's purchase accounted for the most, accounting for $71.51 \%$. At the same time, the elderly people's satisfaction with the service charge level and service quality was higher, and the proportion of "satisfied" and above attitude was $93.59 \%$ and $96.77 \%$ respectively. In addition, $97.32 \%$ of the elderly said "very satisfied" or "satisfied" with the attitude of service workers, while $96.73 \%$ of the elderly said "very satisfied" or "satisfied" with their professional level. And $96.23 \%$ of the elderly were "very satisfied" or "satisfied" with the diversity of service content, while $97.33 \%$ were "very satisfied" or "satisfied" with the necessity of service content. The elderly people's satisfaction with the service frequency, service timeliness and service complaint channel of the government to purchase the family old-age care service is relatively high, and the satisfaction rate is "very satisfied" or "satisfied" respectively, accounting for $94.6 \%$ and $92.73 \%$ respectively.

\section{The low cognitive level of the government's purchase of home care service}

On the whole, the elderly who enjoy the service have a low level of cognition about the government's purchase of the home care service. From the way of knowing the service, $64.17 \%$ of the elderly are informed by the organization and $34.22 \%$ through the community. Therefore, the understanding of the policy of the elderly with minimum living standard is mainly through the contract of the service undertaking institution. "Signing a contract" means signing an agreement to enter a home with the elderly, taking the agreement as the supporting material for the services provided by the service organization, and providing reasonable and legitimate support for the entry into the home service of the elderly. From the way of signing, the proportion of institutions door-to-door signing accounts for $72.43 \%$, and the proportion of unsigned accounts for $23.24 \%$. The main reason for unsigned medical service is that the community directly notifies the elderly to go to the hospital for physical examination. The results of these two surveys show that the service is not well publicized, leading to the elderly people's understanding of the government's purchase of home care services mainly from the service providers and community workers, and in a weak position of information.

In addition, $59.36 \%$ of the elderly said they knew the name of the service organization, but the survey found that most of the older people were ambiguous about the name of the institution, and some needed to be reminded by the agency personnel. Others know only one or two words in the name of the organization, and very few can be correctly expressed. $89.84 \%$ of the elderly said they knew the service content, but most of the answers were table cleaning and window cleaning. Only $12.90 \%$ elderly people know the price of services, and most of them only know the total amount of services, and the price of each service consumption is not clear, and through the survey, it is found that service agencies deliberately do not mention the price of services because the elderly are more sensitive to the price. The above three items all show that the elderly are in the passive position of "accepting whatever they give" in the whole government purchase of the family old-age care service, and only have a preliminary understanding of the whole service, and their understanding degree is very limited.

It can be seen from the table that only $6.49 \%$ of the elderly who have made active calls for service have not been aware of the telephone number of service organizations. During the visit, the researchers found that the two service providers provided the services in different ways: the domestic service staff took the initiative to provide services to the elderly in a positive manner, or contacted the elderly by telephone. Limited by medical equipment, the hospital provides services by contacting the community and organizing the elderly to go to the hospital for physical examination within a specific period of time. According to the proportion of elderly people receiving services, the proportion of domestic service is significantly higher than that of medical service, which shows that the "door-to-door" factor has a significant impact on the elderly whether or not they receive services, indicating the passive position of the elderly in the service. They lack the enthusiasm and awareness of the initiative to ask for service.

In terms of the number of services received per month, nearly half of the elderly receive services 
only once a month, and there are cases where they receive services only once a month. This shows that the elderly are not highly motivated to purchase home care services, lack the awareness of service subjects, fail to achieve the envisaged effect of helping the elderly to solve problems in time, and also reflect the elderly service policy from the side. The purpose of the service is not understood.

Table 2. Elderly people's recognition with the government's purchase of home care services

\begin{tabular}{|c|c|c|c|c|c|}
\hline $\mathrm{N}=\mathbf{1 8 7}$ & $\begin{array}{l}\text { Community } \\
\text { notification }\end{array}$ & $\begin{array}{l}\text { Institutional } \\
\text { notification }\end{array}$ & $\begin{array}{l}\text { Learn } \\
\text { through } T V \text {, } \\
\text { etc }\end{array}$ & $\begin{array}{l}\text { Child } \\
\text { notificat } \\
\text { ion }\end{array}$ & Other \\
\hline \multirow[t]{2}{*}{$\begin{array}{l}\text { the way of knowing } \\
\text { the service }\end{array}$} & $34.22 \%$ & $64.17 \%$ & $0.53 \%$ & $0.53 \%$ & $0.53 \%$ \\
\hline & $\begin{array}{l}\text { Community } \\
\text { door-to-door }\end{array}$ & $\begin{array}{l}\text { Sign up with } \\
\text { the } \\
\text { community }\end{array}$ & $\begin{array}{l}\text { institutions } \\
\text { door-to-door }\end{array}$ & $\begin{array}{l}\text { Not } \\
\text { signing }\end{array}$ & \\
\hline \multirow[t]{2}{*}{ the way of signing } & $3.24 \%$ & $1.08 \%$ & $72.43 \%$ & $23.24 \%$ & \\
\hline & Yes & No & & & \\
\hline $\begin{array}{l}\text { Whether know the } \\
\text { name of institution }\end{array}$ & $59.36 \%$ & $40.64 \%$ & & & \\
\hline $\begin{array}{l}\text { Whether know the } \\
\text { service content }\end{array}$ & $89.84 \%$ & $10.16 \%$ & & & \\
\hline $\begin{array}{l}\text { Whether know the } \\
\text { service price }\end{array}$ & $12.90 \%$ & $87.10 \%$ & & & \\
\hline \multirow[t]{2}{*}{$\begin{array}{l}\text { Whether call the } \\
\text { agency to request } \\
\text { service }\end{array}$} & $6.49 \%$ & $93.51 \%$ & & & \\
\hline & Once & Twice & Three times & $\begin{array}{l}\text { Four } \\
\text { times }\end{array}$ & $\begin{array}{l}\text { Five times } \\
\text { and more }\end{array}$ \\
\hline $\begin{array}{l}\text { Number of services } \\
\text { received per month }\end{array}$ & $43.02 \%$ & $12.79 \%$ & $16.86 \%$ & $18.02 \%$ & $9.3 \%$ \\
\hline
\end{tabular}

\section{Discussion}

The results showed that there is a great contradiction between the elderly's satisfaction with the government's purchase of home care services and their cognitive level, and the phenomenon of high satisfaction and low cognitive level is prominent. The high satisfaction degree of the elderly may be the low cognitive level that makes the elderly who enjoy the service have the wrong idea, misjudge the subject, and the characteristics of the group, thus affecting the evaluation of the satisfaction degree. Therefore, the following paper will first analyze the reasons for the elderly's low level of cognition about the government's purchase of old-age care services, and explain the reasons from four aspects: the elderly themselves, the government, the institutions and the community. On this basis, further analysis of the elderly service evaluation of the reasons for high satisfaction, among which, the elderly concept factor dominates, the following will focus on the elderly point of view to analyze.

\section{Reasons for the elderly's low cognition of the government's purchase of home care services}

First, the cognitive level of the elderly is limited. For the elderly who receive the government purchase of home care services, on the one hand, they are restricted by their poor educational level and family conditions, and their access to information is extremely limited; moreover, they are insensitive to government policies. TV programs pay less attention to the government's purchase of family pension related news content, which results in its cognition of service completely dependent on the service providers and community workers. On the other hand, the elderly neglect their right 
to service, but also have the responsibility of evaluation and supervision. When receiving services, older people tend to treat the government's purchase of home care services as a "charity", thinking that some people are already satisfied with doing good deeds, thus lowering the demand for the level of service. Institutions or communities will not be too much to learn about the situation, deepening the government purchase of home care services cognitive level restrictions.

Second, the government service project is not perfect, lack of propaganda. On the one hand, when the government buys the service for the aged, there are not specific and imperfect loopholes in the formulation of the principles, standards and conditions of purchasing the service for the aged, and the definition of the scope of the service is not clear, which can easily cause the concept and understanding of the public to be unclear and vague. In particular, older people do not know what services they are receiving. On the other hand, the government buys endowment service propaganda dynamics is insufficient. In the propaganda content, the effective information of the government purchasing the old-age service has not been transmitted to the elderly and the public in time, which has aroused the attention and attention of the elderly. In the form of propaganda, the platform of communication with the elderly is not built, and the process of direct communication with the elderly is lacking, which leads to the inefficiency of communication. In addition, the scope of the government to purchase home care services is very limited, the lack of community education, household details and other effective forms, resulting in the elderly government to buy the home care service awareness is low, and participation is insufficient.

Third, the information guidance of service organizations is inaccurate. One party buys, the government buys the old age service organization, when carries on the service to the old people, lacks the consciousness to provide the comprehensive service information to each old person. Especially the service staff of grass-roots institutions who have the most contact with the elderly do not know the relevant contents of the government to purchase the family old-age care service and can't make a clear explanation to the elderly resulting in the lack of channels for the elderly to understand the information. On the other hand, there is selfishness in the service organization, and there may be some concealment and distortion in introducing and explaining the service. In order to reduce the workload of the service, the elderly have a high degree of recognition, which leads to inaccurate information transmission.

Fourth, community guidance is unscientific. Community workers' understanding of the government's purchase of old-age care services at home is limited to the theoretical knowledge in various documents, and it is not clear what it should be in practice, so it is unable to convey the contents of the government's purchase of old-age care services to the elderly in the community. In addition, the lack of professionalism of community workers may lead to one-sided problems in interpretation, resulting in incomplete information and misinterpretation, which is not conducive to the elderly to the government to purchase home care services for the correct cognition.

Generally speaking, the relationship between cognition and satisfaction is progressive. On the premise of knowing the government's purchase of old-age service items, the elderly can judge further according to their acceptance status in the process of accepting the service items. Finally, the implementation effect of the service items is evaluated and the feedback is satisfaction. However, the survey results show that the elderly generally have high satisfaction with the service. The reason may be that the elderly enjoying the service with low cognitive level have a wrong idea, misjudge the main body and its group characteristics, thus affecting the evaluation of satisfaction.

\section{Reasons for the elderly's high satisfaction with the government's purchase of home care services}

Firstly, the old people generally hold the view of "doing good deeds". The low level of cognition makes the elderly who enjoy the service more regard the service of the staff of the service organization as a kind of charity. In this view, the elderly who enjoy the service often wear "colored glasses", which means that the moral quality of the service personnel is high, and usually give the service personnel "they are too kind" (Li Mou, male, 70 years old) evaluation. In their concept, they have already received the help and service of service personnel. They should no longer ask for and 
displease them. The demand and dissatisfaction will be a betrayal of the kindness of the service personnel, and it is "not knowing the good people" (Bai Mou, male, 61 years old), so they give a higher evaluation of the service.

Second, the elderly think the service is "free". Because the government's propaganda is low, the service information is not smooth, the elderly do not understand the service, and the third party service organization conceals the service content, price and so on in the service process. Older people tend to think they are enjoying services free of charge. In the face of "can enjoy without paying", the elderly are willing to accept that they are "taking advantage", often do not have an objective and fair evaluation, not to mention their dissatisfaction.

Third, older people have lower expectations of service. Philip Kotler defined satisfaction as "a state of pleasure or disappointment that a customer feels through comparing the perceived effects of a product with his expectations." The high degree of satisfaction in this study gave rise to a bias in expectations due to cognitive deficiencies. Elderly people who enjoyed services tended to hold the view that "yes is good, yes is better than no", that is, they thought that they enjoyed the service enough, and did not have a high demand for the content, frequency, and quality of the service. "They came to clean the glass, I'm not saying no." In the survey, there are not a few elderly people who hold this view. They do not know what the service should be. They do not require the standard and quality of the service. If they accept the help, they will be satisfied as long as part of the burden is lightened.

Fourth, the elderly have misjudged the service subject. According to previous studies, such as the 14-year survey of people's livelihood satisfaction in Jinhua City, the perception of the minimum living security group to the government as a whole is better, and the evaluation is higher, so they are satisfied. The degree of satisfaction may stem from the evaluation of the government by the elderly enjoying the minimum living allowance rather than from the service level of the service providers. On the basis of this, it is in the low expectation level of satisfaction, and can't achieve the original intention of the government to buy home care services.

\section{Conclusion}

In this paper, based on typical sampling, two embedded community nursing homes are selected to investigate, interview, and other methods such as field selection, investigation, literature research, etc. It is found that there is a great contradiction between the elderly's satisfaction with the government's purchase of pension services and their cognitive level, and the phenomenon of high satisfaction and low cognitive level is prominent. Based on the findings, this paper makes the following analysis.

Firstly, the reasons for the elderly's low level of cognition about the government's purchase of pension services can be explained from four aspects: the elderly themselves, the government, the institutions and the community. First, the cognitive level of the elderly is limited, second, the government service project is not perfect, lack of propaganda, third, the information guidance of service organizations is inaccurate, and the community guidance is not scientific.

Secondly, the old people's concept factor dominates the phenomenon of high service satisfaction. First, the elderly generally hold the view of "doing good", second, the elderly think that the service is "free", third, the level of the elderly's expectation of service is low, and finally, the elderly misjudge the subject of service.

\section{References}

[1] Luo Guancui, Wang Junfang. The Hong Kong experience of Government purchase of Services and the Development of the mainland. Study and Practice. 2008 (9): 125-130. (In Chinese)

[2] Zhu Meihua. Government purchase of services-an innovation in the social welfare system [J]. Social work, 2004 (8): 8-11. (In Chinese)

[3] Grizzle G A. Measuring State and Local Government Performance: Issues to Resolve before 
Implementing a Performance Measurement System [J]. State \& Local Government Review, 1982, 14 (3): 132-136.

[4] Elinor Ostrom. Institutional incentive and Sustainable Development: a Perspective of Infrastructure Policy. Shanghai Sanlian Bookstore, 2000. (In Chinese)

[5] Cai Lihui. Analysis on the concept and method of Government performance Evaluation [J]. Journal of Renmin University of China, 2002, 16 (5): 93-100. (In Chinese)

[6] Liu Peipei. A study on the performance Evaluation of the Government's purchase of Old-age Services [J]. Shanghai University of Engineering and Technology, 2016. (In Chinese)

[7] $\mathrm{Hu}$ Sui. The practical Dilemma and path Innovation of the performance Evaluation of the Government's purchase of Social Organization Service [J]. Journal of Social Sciences, Hunan normal University, 2015 (4): 110-115. (In Chinese) 